\title{
APPENDIX 1: VERSIFICATION
}

Versification, the Mosul text compared with Leiden.

\begin{tabular}{|c|c|}
\hline Leiden & Begins with Mosul \\
\hline $6: 2$ & Last 7 words of $6: 1$ \\
\hline $13: 4$ & Last 11 words of $13: 4$ \\
\hline $21: 21$ & Last 2 words of $21: 20$ \\
\hline $22: 16$ & Last word of 22:15 \\
\hline 23:8 & Last 4 words of $23: 7$ \\
\hline $23: 11$ & $2^{\text {nd }}$ word of $23: 11$ \\
\hline $24: 44$ & $6^{\text {th }}$ word of $24: 44$ \\
\hline $24: 48$ & Last 3 words of $24: 47$ \\
\hline $26: 13$ & Last 2 words of $26: 12$ \\
\hline $27: 4$ & $5^{\text {th }}$ word of $27: 4$ \\
\hline $27: 27$ & Last 2 words of $27: 26$ \\
\hline $27: 44$ & $12^{\text {th }}$ word of $27: 43$ \\
\hline $27: 45-46$ & $27: 44-45$ \\
\hline $30: 29$ & $6^{\text {th }}$ word of $30: 28$ \\
\hline $30: 30$ & $30: 29$ \\
\hline $32: 1$ & $31: 55$ \\
\hline $32: 2-33$ & $32: 1-32$ \\
\hline $33: 20$ & $4^{\text {th }}$ word of $33: 20$ \\
\hline $40: 21$ & $8^{\text {th }}$ word of $40: 21$ \\
\hline $41: 57$ & $5^{\text {th }}$ word of $41: 57$ \\
\hline $45: 22$ & Last word of $45: 21$ \\
\hline $45: 25$ & $9^{\text {th }}$ word of $45: 24$ \\
\hline $45: 26-28$ & $45: 25-27$ \\
\hline $49: 23$ & Last 2 words of 49:22 \\
\hline $49: 29$ & $3^{\text {rd }}$ word of 49:29 \\
\hline
\end{tabular}


